\title{
Algumas reflexões necessárias sobre o fenômeno sexting na busca de prevenção de riscos para adolescentes em suas relações com as mídias
}

\begin{abstract}
Resumo
Este artigo pretende levar o leitor a refletir sobre uma prática cada vez mais comum entre crianças, adolescentes e adultos, denominada sexting e será dividido em três momentos. No primeiro, é realizada uma breve descrição do que representou a Modernidade em termos de transformações na humanidade e o momento atual, além de uma reflexão sobre a questão da individualidade. No segundo, são feitos alguns apontamentos sobre quem é o adolescente de hoje. No outro momento, é apresentada uma contextualização do fenômeno Sexting, por meio de uma breve revisão conceitual sobre ele apontando, inclusive, para a situação de riscos a que podem se expor os adolescentes ao praticá-lo. Para concluir, aponta-se um caminho a ser trilhado para um necessário estudo da compreensão de adolescentes sobre o sexting.
\end{abstract}

Palavras-chave: Sexting; Educação Sexual; Adolescentes.

Camila Detoni Sá de Figueiredo Universidade do Estado de Santa Catarina - UDESC - SC/Brasil camiladsaf@gmail.com

Sônia Maria Martins de Melo Universidade do Estado de Santa Catarina - UDESC - SC/Brasil soniademelo@gmail.com

\section{Para citar este artigo:}

FIGUEIREDO, Camila Detoni Sá de; MELO, Sônia Maria Martins de. Algumas reflexões necessárias sobre o fenômeno sexting na busca de prevenção de riscos para adolescentes em suas relações com as mídias. Revista Linhas. Florianópolis, v. 17, n. 34, p. 84-102, maio/ago. 2016. 


\title{
Some reflections necessary about sexting phenomenon in the search of preventing risks for teenagers in their relations with media
}

\begin{abstract}
This article intend to guide the reader about a practice very common nowadays between children, teenagers and adults, called sexting, written in three moments. At first, it is accomplished a brief description about what represent Modernity times and its changes regarding humanity and the moment lived today, besides a reflection about individuality issues. Second, we make some notes about who is the adolescent nowadays. Third, the article presented a Sexting contextualization by a brief conceptual review about it, pointing out the risks situation that teenagers may be exposed when practicing it. In conclusion, we intend to show a way to follow in order to achieve a necessary study about teenager's comprehension about sexting.
\end{abstract}

Keywords: Sexting; Sexual Education; Adolescents. 


\section{Introdução}

Para uma reflexão urgente e necessária sobre um fenômeno atual, que se convencionou chamar de sexting, por entendê-la como fundamental na contextualização dessa prática que leva muitos adolescentes, atualmente, a se colocarem em situações de risco pelo uso indevido das redes sociais, levando infelizmente alguns deles ao ato extremo do suicídio. Resgatamos inicialmente algumas breves reflexões sobre o contexto social, econômico e político em que vivemos a partir da chamada Modernidade, até chegar aos dias de hoje.

Para tanto, a metodologia adotada para a produção deste artigo foi a de uma pesquisa bibliográfica e um levantamento de dados sobre o tema. Assim, dividimos o estudo em três momentos: no primeiro, fazemos uma breve descrição das transformações vivenciadas a partir da Modernidade, segundo Berman (1986) e Bauman (2001), até chegar ao momento atual, chamado de "sociedade do espetáculo" por Guy Debord (2003).

No segundo, apresentamos algumas características do adolescente hoje, inclusive em suas relações com as redes sociais, por meio de um diálogo com algumas pesquisas feitas sobre esta temática, considerando que esse jovem já nasceu em um mundo conectado a uma rede social por meio de várias mídias. Diálogo este sempre na busca de algumas respostas para certas perguntas, como: Como pensa e se comporta esse adolescente? Por que práticas de sexting que expõem esse indivíduo nas redes sociais, inclusive colocando-o em situações de risco, estão se tornando cada vez mais comuns, sendo praticadas acriticamente por muitos adolescentes?

No terceiro momento, apresentamos uma breve revisão de alguns conceitos encontrados sobre o fenômeno sexting. Para concluir, apontamos a necessidade de criar caminhos para estudos urgentes sobre a compreensão de adolescentes a respeito do fenômeno como subsídio básico a projetos intencionais de prevenção desses riscos. 


\section{As transformações vivenciadas desde a Modernidade até a Sociedade do Espetáculo}

Na Modernidade, iniciada no século XVI, a partir de movimentos como o Iluminismo, Revolução Industrial, Revolução Inglesa e Reforma Protestante, ocorreu a mudança de dois paradigmas básicos que marcaram a ciência, a economia, os sistemas de produção e trabalho, a política, as relações sociais, a saúde, a cultura e as artes. 0 primeiro refere-se ao entendimento sobre o processo de construção do conhecimento, que passa do idealismo para o materialismo, ou seja, o conhecimento passa a ser construído a partir do que é material, concreto. O segundo paradigma que se transforma é com relação à centralização do conhecimento, ou seja, este passa a estar nas mãos do homem e não mais sob o poder da Igreja, segundo Cardoso, citado por Teixeira em 2005.

Ainda segundo Cardoso, citado por Teixeira em 2005, na Modernidade ocorreram também muitas transformações na economia, pois as relações de produção se reestruturaram, com a emergência do capitalismo. Com essa mudança, o sistema capitalista tornou-se o modo de produção hegemônico e, sendo assim, as relações de produção feudais tornaram-se incompatíveis com o sistema capitalista. Enquanto no sistema feudal a produção visava prioritariamente à subsistência, no capitalismo, o que importa passa a ser o acúmulo do capital.

Portanto, o sistema capitalista, produzido por seres humanos em relações sociais que se engendram nos seus modos de produção de vida, em novos arranjos socioeconômicos, promoveu também uma nova forma de ver o mundo, modificando as relações de trabalho, a educação, a saúde, as artes, as ciências, a política e a economia, enfim, todas as áreas do conhecimento humano.

Segundo Marcuse, citado por Nunes (1996), com o sistema capitalista, o ser humano passa a negar o princípio do prazer. Aliado a isso, com a compulsão tecnocrática que se estabelece, estabelece-se também a produção em massa e a perda do sentido da existência e a alienação do afeto. Essa desumanização foi se construindo a partir das relações sociais vivenciadas nas mudanças ocasionadas pelos contextos social, econômico, político e cultural transformados com o empreendimento da Modernidade. As tecnologias de comunicação, produzidas pelos seres humanos, avançaram e avançam ainda hoje, quantitativa e qualitativamente, subsidiando mudanças significativas no modo 
de vida das pessoas em todo o planeta, conforme nos mostram Berman (1986), Bauman (2001), Turkle (2012) e Debord (2003).

A modernidade, para Berman (1986), pode ser dividida em três etapas: a primeira vivenciada por um sentimento de agitação e turbulência, uma espécie de embriaguez, em que há a expansão das possibilidades de experiência e destruição das barreiras morais, a visualização de novas possibilidades, o início da mudança no comportamento e nas relações entre os seres humanos. A segunda etapa, ocorrida a partir do século XVIII, é marcada pela Revolução Francesa, pelo surgimento das máquinas a vapor, das fábricas automatizadas, das ferrovias e das amplas zonas industriais. Nessa etapa, ocorre o rápido crescimento das cidades e os estados nacionais passam a ter mais poder. Destacam-se também o surgimento dos movimentos sociais de massa, os instrumentos de mídia que comunicam em escalas cada vez maiores e a expansão acelerada do mercado mundial.

Nesse contexto, segundo Nietzsche, citado por Berman (1986), o indivíduo ousa se individualizar por meio da criação de leis próprias, necessárias à autopreservação, autoimposição, autoafirmação e autolibertação. Na terceira etapa, descrita por Berman (1986), a modernidade torna-se incapaz de se organizar e dar sentido à vida. Nesse momento, o pensamento encontra-se estagnado e regredido, embora diversas áreas, como pintura, escultura, romance, teatro e dança, tenham sido prósperas. Destacamos também que nesse período, segundo este mesmo autor, ocorrem muitas invenções no campo da mídia eletrônica e houve muitos avanços nas disciplinas científicas. A partir de 1960, a humanidade passa a buscar um sentido para sua existência, ao tentar conectar presente com o passado e futuro.

Já para Bauman (2001), nessa busca ocorre a transformação de nosso mundo em um aglomerado de grupos de interesse privado, material e espiritual, com a destruição de uma forma vital de espaço público.

Ainda segundo esse mesmo autor, a modernidade se divide em dois momentos distintos: a modernidade pesada, em que o interesse era por grandes volumes, pois a riqueza e o poder eram conceitos geográficos, e o controle era feito pelo tempo rotinizado e a modernidade leve, fluída, em que o controle se dá pelos elos que ligam as escolhas individuais em projetos e ações coletivas. Escolhas individuais como, por 
exemplo, participar das redes sociais e postar fatos sobre a vida cotidiana na rede através de textos ou imagens. Essa exposição da vida cotidiana, usando as mídias, se relaciona diretamente com ações coletivas pois, uma vez que uma imagem ou mensagem é colocada na rede, ela se espalha como um vírus por meio de ação coletiva e todos podem ter acesso às postagens. Dessa forma, é como se vivêssemos em um eterno panóptico, um big brother da vida real, em uma Sociedade do Espetáculo, conforme nos aponta Debord (2003).

Segundo Debord (2003), a economia hoje tem como principal mercadoria a imagem criada sobre a vida cotidiana. Na Sociedade do Espetáculo, segundo Debord (2003), as pessoas representam, criam imagens de si visando chamar a atenção e atender ao padrão estabelecido como hegemônico pelo atual contexto social, cultural, econômico e político. Segundo Turkle (2012), colocamo-nos na rede de forma superficial e assim, sentimo-nos sozinhos, mesmo numa multidão.

Tapscott (2010) chama essa geração de Geração Internet ou Geração Digital. Para esse autor, em 2008 o indivíduo mais velho dessa geração fez 31 anos, isto é, há 36 anos nasceram os primeiros indivíduos em um mundo conectado. No Brasil, o uso da internet iniciou, segundo Guizzo (1999), em setembro de 1988, quando no Laboratório Nacional de Computação Científica (LNCC), localizado no Rio de Janeiro, conseguiu-se acesso à Bitnet, por meio de uma conexão de 9600 bits por segundo estabelecida com a Universidade de Maryland, nos Estados Unidos da América. As conexões inicialmente foram feitas em um setor acadêmico e, somente em 1994, foi aberta para usuários domésticos e empresas, abrindo-se possibilidades, a partir daí, para a expansão do acesso, portanto, para o mundo e nele, acesso para os nossos adolescentes. A seguir, dialogaremos com duas importantes pesquisas que mesmo sendo realizadas há alguns anos, em 2007 e em 2010, trazem dados importantes sobre as relações de adolescentes com a internet e nela, com as redes sociais.

Segundo Belloni (2007), em uma pesquisa realizada em quatro municípios da grande Florianópolis, entre 2002 e 2007, o acesso e uso da internet em nosso país ainda era marcado por desigualdades. Essa pesquisa mostrou semelhanças e diferenças no que diz respeito à relação entre jovens e internet, se comparados a jovens de países ricos. Foram entrevistados 373 jovens, desses, $73 \%$ já tinham utilizado a internet somente 
“algumas vezes". Uma das conclusões dessa pesquisa foi que o Brasil, por ser um país periférico do dito novo mundo, incorpora rapidamente as inovações técnicas, mas sempre na medida das possibilidades socioeconômicas de cada indivíduo. Ou seja, o acesso às novas tecnologias também é marcado pelas desigualdades socioeconômicas.

Belloni (2007) revelou também que os maiores utilizadores estão entre os alunos de escolas particulares. Essa mesma pesquisa investigou as representações dos jovens quanto à internet, com algumas perguntas. A primeira, referente ao significado da internet. Dentre os 225 jovens que responderam a questão, $51 \%$ disseram que a internet tem a função de comunicação da rede mundial de computadores, $28 \%$ indicaram a função de acesso ao conhecimento e à educação. Somente $22 \%$ apontaram a função de informação e $9 \%$ indicaram a internet como lazer. A segunda foi respondida por $70 \%$ dos jovens e dizia respeito à importância da internet na vida das pessoas. Deste total, 41\% enfatizaram a função da informação e $26 \%$ consideraram a internet importante para acesso ao conhecimento e à educação. Apenas 15\% destacaram a função de comunicação interativa, que é a função mais presente entre os jovens, também dados desta pesquisa. Uma minoria, 0,6\% apenas, apontou a internet como importante para o lazer, enquanto $19 \%$ lembraram a utilidade geral da rede. Dos jovens entrevistados, $81 \%$ concordaram que é fácil aprender a utilizar a internet. Com relação à possibilidade da internet substituir a escola, 79\% não concordam com essa ideia, enquanto uma minoria significativa (18\%) já considera essa possibilidade.

Outro ponto importante dessa pesquisa de Belloni (2007) foi quando a mesma foi direcionada à compreensão da acessibilidade e dos modos de uso da rede pelos jovens. Para esta categoria, voltaram-se os estudos feitos aos dados referentes aos 271 jovens utilizadores mais ou menos regulares. Neste grupo, foram levantados alguns aspectos referentes ao uso da internet em casa e qual a ação dos pais diante disso. Sobre a importância do grupo de pares e mídias, bem como a importância da escola e da família com relação à descoberta de novos sites, notou-se que: $76 \%$ descobrem novos sites com amigos; 47\% descobrem através das mídias (TV, rádio, revista e jornal), um grupo menor indica os professores ( $8 \%$ ) ou os pais (3\%) como fonte de informação sobre novos sites. A pesquisa de Belloni (2007) mostrou ainda que, segundo os jovens entrevistados, $44 \%$ dos 
pais tentam exercer controle sobre o uso da internet contra $48 \%$ dos pais que não percebem a internet como algo negativo ou perigoso, sendo as restrições feitas com relação ao tempo gasto e ao custo da conexão. As práticas dos jovens, mais frequentes são: bate-papo (46\%) e interação via e-mail (46\%); estudo (23\%); navegar ao acaso (34\%); fazer download de jogos (30\%).

Destes dados apresentados por Belloni (2007), queremos destacar ainda o seguinte: a maioria dos jovens (51\%) utiliza a internet para se comunicar, sendo que $15 \%$ deles se comunicam de forma interativa e, desse percentual, somente $44 \%$ são orientados, segundo os próprios jovens. Mesmo que somente 15\%, em 2007, utilizasse a internet como ferramenta de comunicação interativa, o fato de que isso era feito com pouca ou quase nenhum orientação já deveria ser considerado um sinal de alerta para educadores em geral, desde aquela época. Pois os dados pessoais como telefone, endereço e rotina diária que são colocados na rede por crianças, jovens, adultos e também idosos, podem ser visualizados por criminosos e esse elemento pode ser uma das causas que os colocam em situação de risco. Importante também destacar que os indivíduos que se encontram na fase da adolescência, nosso público alvo, possuem, segundo Aberastury (1992), sentimento de onipotência, ou seja, de crer que nada de ruim irá Ihes acontecer e se ninguém os alerta com frequência sobre esses riscos, a tendência desse grupo é a de considerar que os riscos não existem.

Além dessa pesquisa realizada por Belloni (2007), encontramos registros de que o Fundo das Nações Unidas para a Infância - UNICEF - realizou no Brasil, em 2013, uma pesquisa sobre o uso da internet por adolescentes, na qual foram entrevistados 2002 indivíduos, entre 12 e 17 anos.

Essa pesquisa utilizou o censo de 2010 para fazer a análise dos dados. Segundo o censo, tínhamos, em 2010, 21 milhões de adolescentes no Brasil, sendo que destes, 70\% tinham acesso à internet, o que equivale a 15 milhões de adolescentes brasileiros; portanto, tínhamos seis milhões de adolescentes brasileiros sem acesso a ela. Entre os que não tinham acesso, encontravam-se os mais pobres, os que viviam na zona rural, os com baixa escolaridade e os adolescentes indígenas, segundo os dados levantados na época. Na região sul do Brasil, 79,30\% dos adolescentes tinha acesso à rede, contra 20,70\% que ainda não possuíam acesso. Com relação ao acesso por idade, tínhamos a seguinte 
distribuição: de 12 a 14 anos, 67\% tinham acesso à rede e, de 15 a 17 anos, 78,5\% dos adolescentes. Dos entrevistados 64\% usavam a internet diariamente, 26\% utilizavam-na semanalmente e 9\% utilizavam-na somente uma vez por mês ou menos. Em relação ao tipo de uso que faziam da internet, as respostas ficaram assim distribuídas: $76 \%$ usam para diversão, 66\% para fazer amizades, 61\% para trabalho escolar e 40\% para buscar informações. As ferramentas utilizadas assim se distribuíram nas respostas: redes sociais $84 \%$, jogos online $69 \%$, e-mail $59 \%$ e mensagens, $57 \%$.

\section{Conforme registra o documento da UNICEF (2013):}

... as ferramentas que dependem de uma atividade autoral mais intensa são pouco utilizadas pelos adolescentes. Um dos desafios da inclusão é estimular os adolescentes não somente ao acesso mas também à produção de conteúdo. Isso significa mostrar que é possível ir além da consulta e do bate-papo e partir para a produção de ideias... (UNICEF, 2013)

A seguir, dois gráficos extraídos da pesquisa que mostram o uso das ferramentas pelos adolescentes:

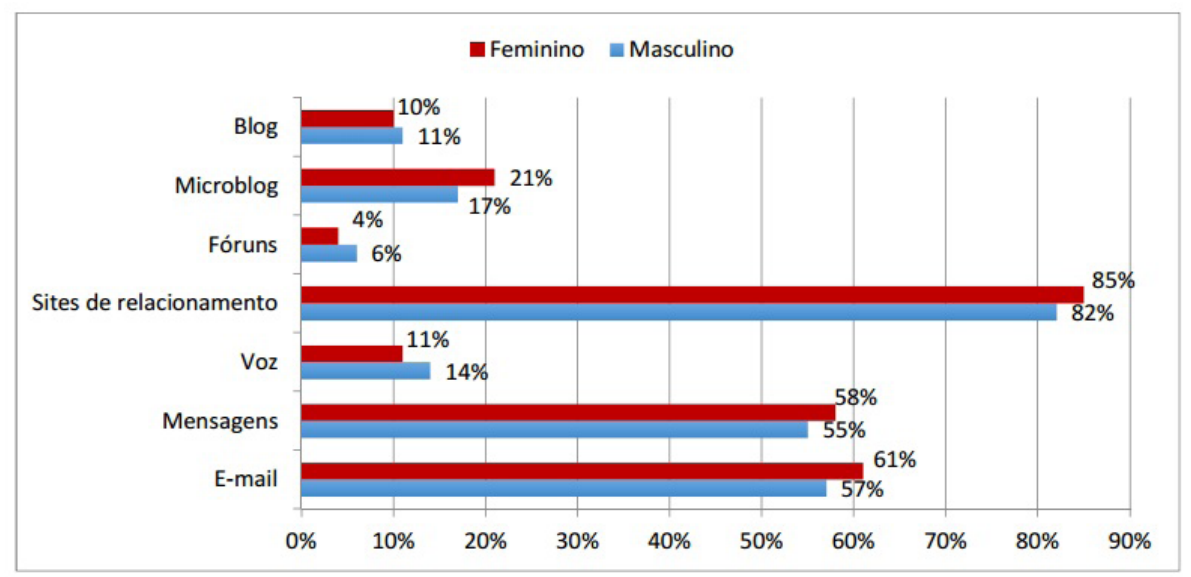

Figura 1: Uso de ferramentas por gênero. Fonte:

http://www.unicef.org/brazil/pt/br_uso_internet_adolescentes.pdf

Obs.: $\mathrm{O}$ universo de adolescentes considerado neste gráfico refere-se a todos os entrevistados que já utilizaram um computador e internet nos três meses anteriores a esta pesquisa. 


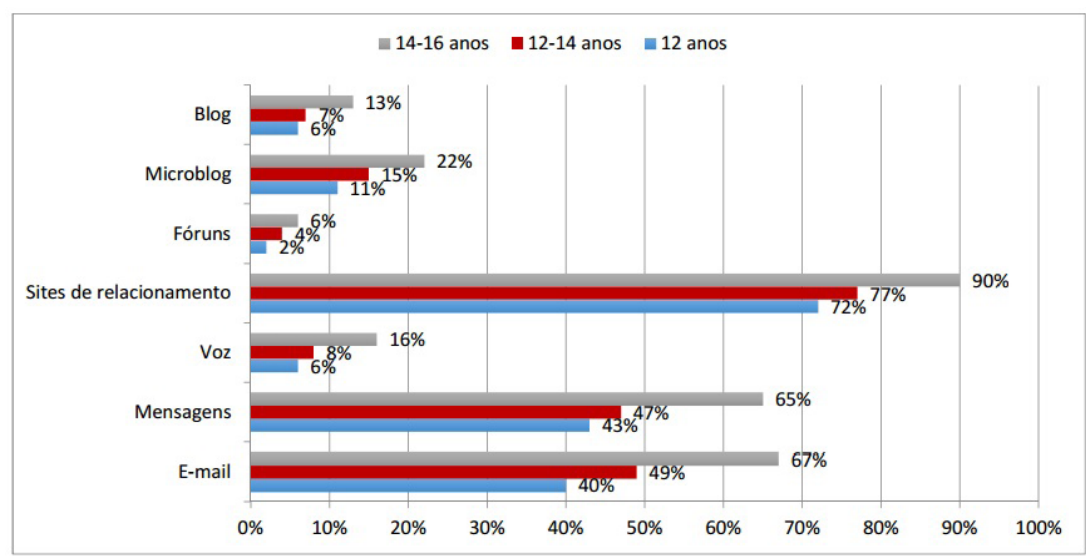

Figura 2: Uso de ferramentas por idade. Fonte: http://www.unicef.org/brazil/pt/br_uso_internet_adolescentes.pdf Obs.: O universo de adolescentes considerado neste gráfico refere-se a todos os entrevistados que já utilizaram um computador e internet nos três meses anteriores a esta pesquisa.

Percebemos que o uso das redes sociais na época aumentava entre adolescentes de 15 a 17 anos. Enquanto 75\% dos adolescentes de 12 anos afirmavam ter um perfil, esse número saltava para 90\% entre os adolescentes de 15 a 17 anos.

Sobre as redes sociais e a segurança, a mesma pesquisa da UNICEF no Brasil (2013) nos mostra os seguintes dados: $65 \%$ dos entrevistados afirmavam nunca ter ativado a informação de sua localização nas redes sociais e $24 \%$ só diziam onde estão diante de certas condições. Apenas 10\% dos entrevistados afirmaram que sempre indicavam sua localização quando usavam as redes sociais. Entretanto, esse comportamento não é homogêneo entre as regiões brasileiras. Enquanto apenas 7\% dos adolescentes da Região Sul sempre informavam a sua localização, esse número subiu para $22 \%$ na Região Norte.

Ainda segundo essa pesquisa, sobre adicionar desconhecidos, 21\% dos entrevistados afirmou incluir desconhecidos em suas redes, sendo que $33 \%$ dos adolescentes disseram que faziam dentro de determinadas condições.

Continuando a leitura dos dados da UNICEF em sua pesquisa no Brasil, encontramos registrado que, embora a maioria dos adolescentes (61\%) não tivesse o costume de encontrar as pessoas que conheciam via redes sociais, foi relativamente alta (39\%) a porcentagem dos entrevistados que já tinham vivenciado essa experiência. Os encontros foram mais comuns entre os meninos (48\%) do que entre as meninas (31\%). 
Essa pesquisa da UNICEF explorou também a exibição de imagens. Sobre isso, foi bem mais comum postar fotos (66\%) do que vídeos (23\%) na internet. Entre os que disponibilizam fotos, $91 \%$ incluíam imagens de sua vida pessoal, em que apareciam familiares, sua casa ou o próprio adolescente. No caso dos vídeos, $68 \%$ dos que postaram incluíram cenas da vida pessoal. Entre as regiões brasileiras, Norte (93\%), Sudeste (94\%) e Sul (92\%) se destacaram por maior exibição de fotos pessoais, em comparação com as regiões Nordeste (89\%) e Centro-Oeste (86\%). Com relação ao gênero, enquanto 94\% das meninas exibiram imagens, $88 \%$ dos meninos também o fizeram. Entre os entrevistados, apenas 19\% afirmaram já ter acessado sites com conteúdo sexual, restrito a menores de 18 anos. Mas, notando que na metodologia da pesquisa permitiu-se a presença dos pais durante as entrevistas, há que se ponderar que isto talvez possa ter influenciado nas respostas referentes a esta questão.

O controle do acesso à internet também foi investigado pela pesquisa em pauta: 54\% afirmaram ter algum tipo de acompanhamento, 46\% declararam não ter nenhuma forma de controle dessa atividade por parte de seus pais.

Algumas reflexões necessárias no que se refere aos dados demonstrados pela pesquisa na relação dos adolescentes brasileiros quanto ao uso que fazem das redes sociais na internet: o fato de $19 \%$ dos adolescentes que acessaram a internet afirmarem já ter acessado sites de conteúdo impróprio para menores de 18 anos, indica a exposição de um grupo expressivo a conteúdos inadequados em sua fase de desenvolvimento. Também o dado de $48 \%$ dos meninos e $31 \%$ das meninas já terem encontrado pessoalmente alguém que só haviam conhecido pela internet, pode ser um indicador de que a rede ajuda a ampliar as possibilidades de conhecer novas pessoas, mas também pode revelar uma exposição a situações de vulnerabilidade, caso não sejam tomados os cuidados adequados.

Entendemos que o compartilhamento não cuidadoso de informações pessoais, a exposição de situações de seu cotidiano, de fotos de toda natureza e a permissão de acesso livre de qualquer pessoa aos seus dados, são fatores que tornam o/a adolescente vulnerável às pessoas que queiram manipular essas informações para constranger, assediar ou expor em fotos e/ou vídeos com situações íntimas daquele adolescente 
postadas por ele mesmo, o que tem acontecido com o fenômeno que se convencionou chamar de sexting.

A possibilidade de implicação dos adolescentes em situações com chances de riscos nesse fenômeno fica ainda mais potencializada com os dados registrados também na pesquisa em tela de que os adolescentes se sentem mais discriminados na vida real do que na internet. Enquanto $14 \%$ dos adolescentes revelaram já ter sofrido algum tipo de discriminação na vida real, quando perguntados se já haviam sofrido algum tipo de discriminação na internet, o percentual foi de apenas 6\%, o que aponta que esse espaço virtual pode momentaneamente Ihes dar a falsa segurança de que ali serão mais aceitos do que na vida real.

Entretanto, contraditoriamente, quando perguntados se já presenciaram situações de discriminação ou assédio contra outras pessoas na internet, 14\% já viram alguém ser abordado insistentemente por pessoa desconhecida; 10\% já viram alguém ser abordado com conteúdo sexual ou pornográfico; $27 \%$ já viram alguém ser discriminado por causa de sua raça/cor e $22 \%$ já viram alguém ser desrespeitado por gostar de alguém do mesmo sexo.

Essa contradição, a par de outras que podem ser muito comuns nessa etapa da vida de nossos jovens, pode ter levado os pesquisadores da UNICEF no Brasil a dar o seguinte alerta:

\footnotetext{
Para os adolescentes, a Internet é uma grande biblioteca; um lugar para fazer amizades; um caminho para o avanço profissional; e um local que possibilita contato com outros povos. Num balanço geral sobre os dados obtidos nesta pesquisa, é possível afirmar que os adolescentes vêm fazendo um uso da Internet que demanda maior apoio, orientação e acompanhamento dos adultos. (UNICEF, 2013)
}

Enfim, é nesse contexto da era digital e da sociedade do espetáculo que vive o adolescente brasileiro, que, segundo as pesquisas com as quais dialogamos, usa a internet como fonte de informação e lazer, vivendo em um mundo cada vez mais conectado em rede. 
Como vimos nessas pesquisas, a de Belloni iniciada em 2002 e encerrada em 2007, referente à região da Grande Florianópolis e a da UNICEF - Brasil, finalizada em 2013, as mesmas confirmam com seus dados que se comunicam, que a população jovem tem tido cada vez mais acesso à internet, às redes sociais e aos aplicativos e a maioria desses jovens o faz sem supervisão, sem orientação, pois, segundo Belloni, na região da Grande Florianópolis, entre 2002 e 2007, 48\% dos pais dos entrevistados não viam o acesso à internet como algo perigoso e, segundo a pesquisa da UNICEF - Brasil, ainda em 2013, 46\% dos pais não supervisionavam o uso da internet.

O mundo conhecido e vivido por esses jovens é, portanto, um mundo quase que permanentemente conectado a uma rede, em que os indivíduos revelam a outros fatos de suas vidas cotidianas, sem perceber que essa prática, se realizada acriticamente, pode colocá-los em situação de risco.

Registramos que certamente, além dos jovens, adultos e idosos também estão expostos a riscos na rede ao compartilhar textos, pensamentos, emoções e imagens na internet, mas a adolescência é uma etapa de vida mais vulnerável, por suas próprias características apontadas em vários estudos sobre essa fase da vida do ser humano.

Nessa sociedade se encontram as pessoas, como diz Turkle (2012), sozinhas e juntas, ou seja, a medida que compartilho minhas ideias, pensamentos, emoções e fatos de minha vida na rede, não me sinto tão só, tenho atenção por meio das curtidas, dos feedbacks recebidos, das cutucadas. Além disso, é mais fácil lidar com uma tela, pois à medida que o indivíduo deseja não mais se relacionar, basta desligar o computador, sair da rede ou não responder o e-mail.

E essas maneiras de se relacionar com o mundo virtual vão também influenciando os adolescentes na sua maneira total de viver o mundo, inclusive no que se refere a sua dimensão da sexualidade. São reflexos do que encontramos muito bem registrado pela pesquisadora Amparo Caridade em capítulo de livro de Ribeiro (1999):

O indivíduo constrói-se em seu tempo, em sua cultura, em seu cotidiano. Nessa construção ele vai adquirindo referências tanto dos valores do contexto cultural em que se insere como das marcas que escreveu em seu corpo, em seu imaginário, a partir dos processos educacionais aos 
quais esteve submetido. Um jogo de força se estabelece entre o cultural e o pessoal e o acompanhará por todo o seu viver. Nos dias atuais o indivíduo confronta-se com uma cultura espetacular e narcisista e as referências da construção de sua sexualidade se dão em meio a um contexto de aparências temporalidades e um culto excessivo ao corpo e ao eu. (RIBEIRO, 1999, p. 15)

Portanto, pode-se perceber que o contexto atual influencia as manifestações da sexualidade; se a sabemos dimensão humana inseparável do existir de toda pessoas, e se considerarmos que essas manifestações se transformam à medida que o ser humano se transforma em suas relações sociais, sempre sexuadas, na produção de seu modo de vida. Destacamos ainda que esse contexto descrito por Caridade (1999), que trata da questão da dimensão da sexualidade humana, também tem como fundamento o conceito de Sociedade do Espetáculo. Segundo Caridade (1999), a sexualidade é veiculada na mídia como marketing para seduzir o mercado, para erotizar um produto. Dessa forma, a sexualidade perde seu sentido relacional e assim, o outro já não conta como sujeito, mas como objeto. Considerando a sexualidade vivida sem seu sentido relacional, veiculada na mídia como marketing, eu, adolescente, que vivo nesse mundo em que sou um consumidor, mas também coinovador ${ }^{1}$ (Tapscott, 2010) desses produtos, posso utilizar a vivência de minha sexualidade para criar um produto e lançá-lo no “mercado". E pode esse adolescente, sem supervisão e apoio, "lançar esse produto, ele mesmo", no mercado virtual, numa aparentemente inocente imagem íntima compartilhada numa rede que não tem nada de privada, é pública, mesmo que assim para os jovens muitas vezes não pareça.

Portanto, os seres humanos hoje, dentre eles nossos adolescentes, além de consumidores, são autores de conteúdo que é colocado na internet, nas redes sociais e nos aplicativos (Tapscott, 2010). Dessa forma, ao enviar, compartilhar, publicar, postar imagens íntimas minhas ou de terceiros na rede, estou praticando o que estudiosos hoje chamam de sexting. Para adultos, uma possibilidade de estabelecer jogos sexuais, para os adolescentes um fator de risco, pela sua vulnerabilidade.

\footnotetext{
${ }^{1}$ Os adolescentes e jovens da geração internet são, enquanto consumidores, coinovadores dos produtos e serviços com seus fabricantes. (Tapscott 2010, p. 21)
} 
O primeiro uso do termo sexting foi em um artigo publicado 2005, no Sunday Telegraph Magazine ${ }^{2}$. Após esse, outros estudos sobre sexting têm sido desenvolvidos em vários países, como Reino Unido, Austrália, Estados Unidos, Canadá, Alemanha, Brasil, dentre outros. A maior parte das discussões é sobre o enquadramento do sexting em comportamento de risco quando envolve crianças e adolescentes. Pela leitura de vários artigos sobre o tema, percebemos que, por exemplo, na Austrália e nos Estados Unidos, já há uma discussão sobre até que ponto o sexting pode ser considerado um comportamento relacionado aos tempos contemporâneos e até que ponto expõe crianças e adolescentes a riscos e, sendo assim, deve então essa forma de sexting ser enquadrada como pornografia, abuso sexual ou pedofilia.

Nos Estados Unidos, entre 2009 e 2012, a legislação sobre sexting envolvendo menores, foi promulgada nos seguintes estados: Missouri, South Carolina, Arizona, Illinois, Florida, Nevada, New Jersey, New York, Rhode Island, Texas, Hawaii, Pennsylvania e South Dakota (National Conference of State Legislatures).

Segundo Agustina e Duran (2012), em pesquisa sobre estudos realizados acerca da temática, há uma dificuldade entre os pesquisadores em estabelecer critérios conceituais comuns sobre o que é sexting. Esta dificuldade refere-se à definição de quais atividades relacionadas ao sexo podem ser englobadas nesse fenômeno, com diversas divergências oriundas também nos estudos quanto a questões metodológicas e também à faixa etária dos indivíduos pesquisados.

O conceito de sexting que utilizamos é a união do conceito de Lenhart (2009) e o de Agustina e Duran (2012). O primeiro conceito, de Lenhart (2009) foi encontrado em estudos feitos por Agustina e Duran (2012), que define sexting como o envio ou recebimento de imagens ou vídeos íntimos no celular; e o segundo é o de Agustina e Duran (2012), que definem o fenômeno como enviar, postar, receber ou compartilhar uma mensagem excitante para alguém usando mídia eletrônica ou envolvendo uma imagem/vídeo seu, seminu ou nu. Segundo esses dois conceitos unidos, sexting pode ser definido como o envio, postagem, recebimento e compartilhamento de imagens ou

\footnotetext{
${ }^{2}$ Disponível em http://finslab.com/enciclopedia/letra-s/sexting.php, no dia 11 de março de 2015, às 14 h20.
} 
vídeos íntimos, ou de mensagens excitantes ou ainda de uma imagem/vídeo seu, seminu ou nu por meio do celular e das mídias eletrônicas (computador, redes sociais, internet).

Fica evidenciado, de uma maneira geral, nas pesquisas realizadas sobre o tema que, nas redes sociais como Facebook e Twitter, os jovens praticam sexting como uma atividade de sua vida diária. Para refletir sobre o sexting é preciso considerar esse contexto e buscar compreender o que acontece nos dias de hoje e porque os jovens estão aderindo a essa prática, quais os riscos reais e como pais, mães e de mais responsáveis na família e os profissionais da educação nas escolas, podem e devem orientar seus filhos e filhas, alunos e alunas sobre essa questão.

Não há pretensão aqui de esgotar esse assunto, visto que há outras categorias a serem exploradas para aprofundar essa questão, como: Qual a real compreensão dos jovens sobre isso? Será que crianças e adolescentes percebem que podem se colocar em situação de risco ao interagir acriticamente na internet e, especialmente, ao praticar o sexting? Como os pais e professores compreendem essa prática? Como estão os jovens sendo orientados sobre o respeito ao direito do outro, já que uma das faces do sexting como risco é a exposição não autorizada do material produzido, por e para outros, para além daquela pessoa que é a destinatária original?

Temos que, com urgência, discutir intencionalmente com nossas crianças e jovens valores e atitudes que os preparem positivamente em relação ao uso consciente e seguro das possibilidades que brotam com o uso da internet, das redes sociais e de qualquer aplicativo ali hospedado.

Ao finalizarmos este artigo, relembramos algumas questões iniciais levantadas para refletir, como as características da Modernidade e como ela transformou e continua a transformar o ser humano, e de que forma ela contribuiu para a construção do atual contexto, quais as características do jovem de hoje e o que é sexting. É importante ressaltar também que a tecnologia, em suas várias expressões de ferramentas midiáticas, faz parte da vida do ser humano e é criada por seres humanos, sempre envolta em intenções em seus produtos e programas, não podendo ser considerada espaço de mensagens neutras. 
Por serem produtos das relações humanas, no caso das mídias (computador, internet, redes sociais e aplicativos) não podemos afirmar que são elas que, necessariamente, apenas dificultam nossas vidas e nos trazem problemas. Segundo Kenski (2007), as tecnologias e suas expressões nos dias de hoje podem sim facilitar nosso cotidiano, pois o problema na verdade é o que produzimos nelas e o uso que fazemos delas.

Para compreendermos os novos fenômenos, como o sexting, são necessários estudos aprofundados sobre muitas das questões levantadas neste artigo, como por exemplo, sobre o contexto atual em que jovens estão se expondo para chamar a atenção, e as consequências desse contexto para sua educação. Um estudo envolvendo jovens, familiares e educadores com o intuito de desvelar qual a compreensão deles sobre o fenômeno sexting seria uma contribuição valiosa como um ponto de partida importante para desvelarmos as razões desse comportamento e seus reflexos nos espaços educativos formais e não formais, visando subsidiar novas propostas pedagógicas mais adequadas aos tempos em que vivemos. Propostas essas que possam proteger nossas crianças e jovens dos riscos advindos de um uso indevido, acrítico das redes sociais e de outros produtos disponíveis na internet. 


\section{Referências}

AUGUSTINA, Jose; Esperanza Gómez Duran. Sexting: Research Criteria of a Globalized Social Phenomenon. Archives of Sexual Behavior, v.41, p. 1325-1328, dec. 2012. Disponível em: <http://link.springer.com/article/10.1007/s10508-012-0038-o\#page-1>. Acesso em: 29 de out. 2013.

BAUMAN, Zygmunt. Modernidade líquida. Rio de Janeiro: Jorge Zahar Ed., 2001.

BELLONI, Maria Luiza; GOMES, Nilza Godoy et al. Caracterização do público jovem das tecnologias de Informação e Comunicação: Autodidaxia e Colaboração ( $2^{\text {a }}$ fase). Florianópolis, Universidade Federal de Santa Catarina, Relatório de pesquisa apresentado ao CNPq, 2007.

BERMANN, Marshall. Tudo o que é sólido desmancha no ar: a aventura da modernidade. Trad.: [Carlos Felipe Moisés e Ana Maria L. Loriatti]. São Paulo: Companhia das letras, 1986.

CARIDADE, Amparo. A construção cultural da sexualidade. In RIBEIRO, Marcos. O prazer e o pensar: orientação sexual para educadores e profissionais da saúde. São Paulo: Gente, 1999.

DEBORD, Guy. A sociedade do espetáculo. [S. I.]: EE-BooksBrasil, 2003. Disponível em: <http://www.ebooksbrasil.org/adobeebook/socespetaculo.pdf. >. Acesso em: 20 out.2013.

DONALD Roberts; FOEHR, Ulla; RIDEOUT, Victoria. Generation M: media in the Lives of 818 Year-olds. [s. I.] : A Kaiser Family Foundation Study, 2005. Disponível em: <http://kaiserfamilyfoundation.files.wordpress.com/2013/01/generation-m-media-in-thelives-of-8-18-year-olds-report.pdf.> Acesso: 11 out. 2013.

GUIZZO, Érico Marui. Internet: O que é, O que oferece, como conectar-se. Editora Ática. São Paulo, 1999.

KENSKI, Vani Moreira. Educação e tecnologias: o novo ritmo da informação. Campinas, SP: Papirus, 2007.

LENHART, Amanda. (2009, December 15). Teens and sexting. Retrieved from http://www.pewinternet.org/*/media//Files/Reports/2009/PIP_Teens_and_Sexting.pdf

NUNES, César Aparecido. Filosofia, sexualidade e educação: as relações entre os pressupostos ético-sociais e histórico-culturais presentes nas abordagens institucionais sobre a educação sexual escolar. 1996. Tese (Doutorado em Educação) - Universidade Estadual de Campinas. Campinas, SP, 1996.

RIBEIRO, Marcos Ribeiro. O prazer e o pensar: orientação sexual para educadores e profissionais de saúde. São Paulo: Editora Gente, 1999. 
TAPSCOTT, Don. A hora da geração digital: como os jovens que cresceram usando a internet estão mudando tudo, das empresas aos governos. Rio de Janeiro: Agir Negócios, 2010.

TEIXEIRA, Elizabeth. As três metodologias: Acadêmica, da Ciência e da Pesquisa.

Petrópolis, RJ: Vozes, 2005.

TURKLE, Sherry. Alone together: why we expect more from technology and less from each other. Philadelphia USA: Basic Books, 2012.

UNICEF - Fundo das Nações Unidas para a Infância. O uso da internet por Adolescentes. Local, 2013. Disponível em

http://www.unicef.org/brazil/pt/br_uso_internet_adolescentes.pdf. Acesso : 12 de março de 2015 .

Universidade do Estado de Santa Catarina - UDESC

Programa de Pós-Graduação em Educação - PPGE

Revista Linhas

Volume 17 - Número 34 - Ano 2016 revistalinhas@gmail.com 